\title{
Desertification and Migration
}

\author{
Milton H. Saier Jr.
}

Published online: 6 June 2007

(C) Springer Science + Business Media B.V. 2007

With the world's forests, farm areas and grasslands in retreat, only the deserts are expanding. The UN estimates that 6 million hectares of productive land, an area almost half the size of England, is lost to desertification every year. Arable land per person declined from 0.32 ha in 1962 to 0.21 ha in 1998 and is expected to drop further to 0.16 ha by 2030 . Consequently, each year there are fewer places for environmental refugees to go. With the supply of ecologically healthy land shrinking, there is increasing pressure for the world's expanding human population to migrate. This pressure is enhanced by global warming caused by wasteful fossil fuel consumption in rich countries and changes in rainfall patterns accompanied by increased frequencies of drought.

Population growth together with poverty and poor land management require increasing amounts of ecological resources from the shrinking forest areas and agricultural lands that border the world's deserts. Agricultural techniques that improved yields up to the 1990s are now proving less effective. Exhausted land is being stripped of vegetation; crop yields are faltering; and rural populations are being displaced

M. H. Saier Jr. ( $\square)$

Division of Biological Sciences (0116),

University of California, San Diego,

La Jolla, CA 92093-0116, USA

e-mail: msaier@ucsd.edu from their lands in growing numbers. Clearly, this is a dangerously unsustainable situation that puts the future of mankind at risk!

About a quarter of the world's population inhabits drylands with roughly two-thirds of Africa falling into this category; areas near the Sahara are at the highest risk of desertification. The northern Sahara covers at least half of Algeria, Libya and Egypt while the southern Sahara extends into much of Mali, Niger, Chad, Somalia and Sudan. We know from historical accounts that much of this desert was once fertile land that supported advanced societies, those of ancient Egypt, for example. In these areas, deserts are continually advancing so that conflicts over land, already a major problem, are expected to intensify. Climate change will lower water absorption and promote windstorms that turn fertile land into dust bowls. Increasingly restricted habitable land availability is likely to affect all world populations.

Areas of fast population growth with extensive poverty exert the greatest pressures on land use. Niger's population, for example, is growing by $3.4 \% /$ year, with a fertility rate of eight children per woman. Only $14 \%$ of married women there use contraception. Niger's population is projected to more than triple, from 14 million in 2006 to 50 million by 2050 unless drastic preventative measures are taken or massive increases in the death rate result. Just imagine the consequence to the already miserable quality of life!

Climate change and population pressures fuel migration. Yet the capacity of other countries to absorb 
migrants is limited. The impact of Sudan's displaced peoples, where nomads currently fight with farmers over shrinking fertile lands, is greatest on neighboring Chad which already suffers extensive ecological damage. Other continents will be able to take desertification refugees only at the cost of their own ecosystems. Europe, the most likely "overspill" area for the excessive African populations, already suffers from weather extremes. The growing influx of migrants, about 250,000 arrivals per year from Africa, approaching 1,000 per day, has already prompted action by the EU. However, recent waves of economic migration into the EU represent only a taste of the future. In 2005, there were 21 million environmental refugees worldwide, up $6 \%$ from the previous year. The UN concluded that 135 million people globally are at risk of being displaced by desertification in the next 20 years.

The populations of many African countries, including Chad, Eritrea, Ethiopia, Mauritania, Niger, Nigeria, Senegal, Sudan and Somalia, are expected to more than double in 30 years if growth continues at the current rate. In all of these countries, fewer than $20 \%$ of married women use any type of contraception. This results largely from a lack of modern birth control availability.

Other continents are similarly threatened by desertification. With its present population, India now suffers from water depletion although it expects an additional 600 million people by 2050 . China also anticipates water shortages and encroaching deserts. However, it has wisely spared the world with its onechild policy, already decreasing its population by over 400 million people. Even in the Americas where human populations per unit area are still relatively small, wild fires and careless land use are increasing the annual magnitude of desertification. This is likely to continue as our increasing populations continue their practice of wastefulness. Religious rationale for restricting contraception availability should not be tolerated. The USA currently has the highest teen pregnancy rate of all the world's developed countries, a sad reflection of its antiquated birth control policies.

Reversing population growth worldwide would clearly be the most meaningful step towards relieving human misery and stress on global ecosystems. To achieve this goal, it will be essential to provide all people, worldwide, with access to modern methods of contraception as well as education about the advantages of smaller families. Governments need to act quickly, and developed countries need to provide the financial support. It is obvious that in the long run, the donor-developed countries will benefit as much as the recipient developing country.

In 2006, the African Union Ministers of Health unanimously agreed to "adopt a plan of action to ensure universal access to comprehensive sexual and reproductive heath services throughout the continent." Similar enlightened policies are gradually being instigated throughout most of the world - except in the USA where the current political/social atmosphere seems to breed a population of irresponsible ignoramuses, swayed by fundamentalistic Christian doctrine. The USA is unique in many respects, particularly in its obsession with fantasy and its reluctance to accept reality.

Yet, cultural and religious values need not necessarily be a barrier. In the Islamic Republic of Iran, the fertility rate was about seven children per woman throughout most of the 1980s. Then in 1989, the government, recognizing the consequence to the people's welfare, launched a population reduction policy officially backed by a national family planning program. Their efforts achieved replacement family size in a shorter period than for any other country to date. Similar national programs have recently been instigated in Pakistan and other Arab countries.

To further exemplify the dissociation of religion from rational behavior, densely populated Catholic Italy has one of the lowest fertility rates in the world, at an average of 1.3 children per woman; its population is actually shrinking! Italians, nominally more than 95\% Catholic, just don't listen to their Pope on birth control issues. And thank God! With near-desertification in parts of Southern Italy, their shrinking population will help to relieve stress on the environment, sparing the population the agonizing consequences: increased poverty, misery, homelessness, crime and death. We can all learn from the rational behavior of others. Many Americans still need to learn what most of the world already knows.

1. Optimum Population Trust report; http://www. optimumpopulation.org.

2. Hadley Centre for Climate Prediction and Research; http://en.wikipedia.org/wiki/Hadley_Centre.

3. Land resource stresses and desertification in Africa, NRCS, http://soils.usda.gov/use/worldsoils/ papers/ desertification-africa.html.

4. World Population Data Sheet 2006, Population Reference Bureau; http://www.prb.org. 